\title{
Assessing the impact of a minimum income scheme: the Basque Country case
}

\author{
Sara De La Rica ${ }^{1,2}$ (D) Lucía Gorjón ${ }^{2,3}$
}

Received: 23 November 2018 / Accepted: 14 August 2019 / Published online: 29 August 2019

(C) The Author(s) 2019

\begin{abstract}
In this paper, we evaluate the impact of a minimum income scheme (MIS) in the Basque Country, one of Spain's 17 autonomous regions. In particular, we assess whether the policy delays entry into employment for recipients, as well as the extent to which activating policies aimed at enabling recipients of the MIS to enter employment work. To do so, we use administrative data of the universe of individuals registered in the public employment service in the region. On average, the minimum income scheme does not delay entry into employment, although the impact differs from one demographic group to another. Furthermore, active labour market policies designed for this group, in particular training, have a strong positive impact on finding a new job.
\end{abstract}

Keywords Minimum income schemes - Active labour market policies · Poverty · Inverse probability weighting $\cdot$ Propensity score matching

JEL Classification $\mathrm{C} 14 \cdot \mathrm{C} 21 \cdot \mathrm{C} 52$

\begin{abstract}
We appreciate comments from the editor and two anonymous referees, as well as from Luis Miller and Javier Gardeazabal on previous versions of this paper. We are also indebted to participants in the "Workshop on Unemployment and Labor Market Policies" organized in April, 2017 and to the Department of Economics of the University of Alcalá, for their comments.
\end{abstract}

Sara De La Rica

sara.delarica@ehu.es

Lucía Gorjón

lucia.gorjon@iseak.eu

1 University of the Basque Country, Bilbao, Spain

2 ISEAK, Bilbao, Spain

3 FEDEA, Madrid, Spain 


\section{Introduction}

Most European Union Member States currently provide some form of minimum income scheme so as to ensure a minimum standard of living for households when they lack other sources of financial support. The emergence of these schemes dates back to 1992, when a European Council recommendation assessed the need to develop last resort schemes which recognised the basic right of every individual to ensure a decent minimum standard of living. These programmes were part of comprehensive, consistent plans to combat social exclusion. Since then, implementation of minimum income scheme (MIS) across European Countries has varied in coverage and effectiveness. The most widely used are the so-called simple and comprehensive schemes, which basically cover every person/household in need of support, without confining their effects to particular categories of people. ${ }^{1}$

In 2008, the European Council endorsed the objective of combining adequate income support with labour market activation measures so as to facilitate entry of recipients into employment. Following the recommendations, minimum income schemes are therefore a combination of passive and active policies.

Although the implementation of these schemes is progressing in most European countries, albeit heterogeneously, there is no sufficient assessment of their impact on aspects such as poverty and inequality reduction, labour market participation of recipients and/or the impact of activation measures on their recipients in terms of entry. Gorjón (2017) addresses the extent to which the Basque MIS reduces poverty, which is the first and most important aim of minimum income schemes. The author reproduces household income in the absence of MIS in order to compare this counterfactual situation with the real one and hence measure the impact of MIS on reducing several measures of poverty. The author finds that the Basque MIS is very effective at the time of reducing the intensity and the severity of poverty, although the extreme poverty is far away to be eradicated. Our work should be understood as a complementary study to Gorjón (2017), as we pose additional research questions to the Basque MIS system related to the labour market participation of MIS recipients.

Around the world, some pilot projects and ex-ante or ex-post assessments of similar policies can be found. An example of such studies includes Gouveia and Rodrigues (2002), who assess the impact of particular MIS on poverty reduction in Portugal. According to their results, the Portuguese policy measure has a modest effect on reducing poverty incidence, but a substantial effect on alleviating the intensity and severity of poverty. An ex-ante assessment of a proposal in Québec is provided by Clavet et al. (2013). Their result shows that the proposed scheme would have strong negative impacts on labour market participation rates, mostly among lowincome workers. Jones and Marinescu (2018) evaluate the impact of a basic income in Alaska. The authors find no impact on the labour supply. Additionally, SalehiIsfahani and Mostafavi-Dehzooei (2018) evaluate the impact of a universal basic income in Iran on labour supply finding no evidence on its reduction. A different

\footnotetext{
1 See Standing (2003) and Frazer and Marlier (2009) for extensive reviews on the Minimum Income Schemes in Europe.
} 
evaluation by Ayala and Rodríguez (2010) tries to find the factors underlying that MIS recipients leave the programme (off-welfare spell). Using administrative data set for the minimum income programme (Ingreso Madrileño de Integración) of a regional Spanish Government (Madrid), they find that the first off-welfare experience is essential for ex-MIS recipients to lengthen the time spent outside the programme.

A more general review of the related literature passes through the debate of the impact of passive policies on exit to employment. A usual criticism is that cash transfers might reduce unemployed individuals' incentives to work (Ayala and Paniagua 2016). An increase in the reservation wage of the unemployed workers can delay their exit into employment. The literature on passive policies has largely shown that unemployment insurance has negative effects in the transition from unemployment to employment. Rebollo-Sanz and García-Pérez (2015) find that non-insured unemployed workers experience a greater rate of transition to employment than insured workers. Furthermore, Card and Levine (2000) and Meyer (1990) prove that exhaustion of unemployment accelerates transitions towards employment. In the same line, Lalive and Zweimüller (2004), Van Ours and Vodopivec (2006) and Røed and Zhang (2003) conclude that benefits strongly affect the duration of unemployment. Given that the MIS is indefinite by nature, its disincentive impact might be particularly strong.

In order to prevent chronification in unemployment for MIS beneficiaries, compulsory activation measures are directed to them. Some activation measures have been proved to be more effective than others. Card et al. (2010) synthesise the main results in the active labour market policies (ALMP) literature. One of the main results they find is that the impact of the programmes varies over time: training programmes, for example, have more positive impacts after 2 years than in the first one, while guidance services are especially helpful in the short run. However, subsidised public sector jobs and for youth programmes are proved to be less successful.

Surprisingly, we are not aware of any study that assesses both potential impacts of the MIS, as a combination of passive and active policies. Our paper seeks to fill this gap. On the one hand, the MIS might delay recipients on their entry into work, the extended undesirable indirect effect of cash transfers. On the other hand, the activation programmes directed to the beneficiaries may have an accelerating effect into employment. According to Eichhorst and Konle-Seidl (2016), empirical evidence has influenced the design of labour market reforms themselves, not least in the area of active labour market policies and activation. This is precisely the ambitious goal of this paper.

Specifically, our study assesses the impact of a minimum income scheme that operates in a northern region of Spain-the Basque Country, called Renta de Garantía de Ingresos. This region pioneered the introduction of MIS in Spain in 1989. The Basque Country is currently the only Spanish region with a Simple and Comprehensive MIS Scheme. ${ }^{2}$ Given that we use monthly administrative records

\footnotetext{
2 The Basque Country is a small region in the northeast of Spain with an actual population of 2 million (5\% of the Spanish population). The active labour force is over 1 million, and the employment rate is $50 \%$. The Basque Country is among the richest Regions in Spain, with the second highest GDP per
} 
of the Basque Public Employment Service, we have access to the whole universe of unemployed registered individuals at any month from February 2015 to January 2016. With this rich individual longitudinal information, we first assess whether the Basque MIS delays entry into labour market for its recipients. Then, we test the efficacy of policies aimed at enabling its recipients to enter employment. We do this by using the inverse probability weighting methodology, which enables MIS recipients to be compared with a similarly observed fictitious group created by weighting nonrecipients. By doing so, the treatment is dissociated from observed individual characteristics and hence pseudo-randomised. Our results indicate that, on average, the Basque MIS does not, per se, delay entry into work for its recipients. Interestingly, however, the impact differs from one demographic group to another. Furthermore, active labour market policies designed for MIS recipients, in particular training, have a strong positive impact on entry into employment. ${ }^{3}$ The results obtained from this analysis cannot be directly extrapolated to other regions given that regional labour markets in Spain exhibit very different patterns. Hence, the impact of MIS in different regions must be studied separately as it may lead to very different outcomes.

The rest of the paper is organised as follows: Sect. 2 reviews institutional aspects of the MIS implemented in the Basque Country. Section 3 gives a description of the data and the main descriptives of MIS recipients. Section 4 presents the methodological and analytical assessment methods and the empirical findings. Finally, Sect. 5 summarises and concludes.

\section{The minimum income scheme in the Basque Country}

The Basque MIS was introduced in 1989, with the so-called Integrated Plan to Combat Poverty. ${ }^{4}$ In the last few decades, it has undergone several modifications. In 1998, it was given the rank of law, the concepts of "poverty" and "exclusion" were defined, and employment incentives, penalties and infringements were established. The amounts provided and the requisites for recipients have also been modified several times. The latest modification was implemented in 2011 (Act 4/2011). We base the details of our description on that version.

\footnotetext{
Footnote 2 (continued)

capita and the third lowest unemployment rate (9.4\%). The Basque Human Development Index is 0.924, the highest in the country, and at the same level as the Netherlands.

3 A key unsettled question in the ALMP literature and in this paper is whether activation measures affect the outcomes of those who do not participate, via displacement or other general equilibrium effects (Card et al. 2010).

${ }^{4}$ Legislation can be found here: http://www.lanbide.euskadi.eus/rgi/-/informacion/rgi-legislacion-ynormativa/.
} 


\subsection{Eligibility requisites}

The first important point to note is that the Basque MIS is family unit based. ${ }^{5}$ Hence, if an individual is an MIS recipient, all members of the family unit are also MIS recipients. To apply for the aid, applicants must comply with the following eligibility requisites: first, they must show that their family unit income is insufficient to meet basic needs, which means inability to access the goods and services classed as necessary for minimum welfare in society according to the Basque Government criterion of poverty (which is outlined below). The second eligibility condition concerns residency in the Basque Country: in principle, the recipient of MIS must be registered on the census and actually have resided in the Basque Country without interruption for the last 3 years. If applicants can prove 5 years of paid work in the Basque Country, the residence requisite can be relaxed to 1 year instead of three. If none of the above requirements is met, applicants must have been registered for a continuous period of 5 years in the immediately preceding 10 years. ${ }^{6}$

Furthermore, the MIS is considered as a last resort scheme, so applicants must already have applied for all other income aids to which they are entitled. In principle, the scheme is compatible with other income aids or wages of family members, so long as they do not exceed the defined poverty line. In addition, applicants must own no property other than their habitual residence.

\subsection{Coverage}

MIS benefits are transferred to family units on a monthly basis. The amount set by the Basque Government to meet basic necessities varies depending on the minimum wage (MW), the number of people in the family unit, the number of retired persons and whether it is a single-parent household or not. For the period under study, the quantity amounts to $88 \%$ of the (annualised) MW for single-member family units and can reach $125 \%$ of such MW for those with three or more members. In the case of family units with at least one pensioner, those figures rise to $100 \%$ and $135 \%$, respectively. ${ }^{7}$ Single-parent family unit receives a supplementary subsidy. ${ }^{8}$ If there are other incomes in the household, the MIS covers the difference in that amount.

\footnotetext{
${ }^{5}$ The strict difference between a household and a family unit is that given that the household relates to the physical space, more than one family unit can live in the same household. However, along the paper, the two terms will be treated indistinctly.

${ }^{6}$ For particular groups, such as those who receive a public sector pension or have been victims of domestic abuse, there is no need to prove work experience and only 1 year of residence in the Basque Country is required.

${ }^{7}$ Standard national minimum wages are provided at monthly rates. When the minimum wage is paid for more than 12 months per year, data are adjusted to take these payments into account. For instance, for Spain, where it is paid for 14 months a year, the minimum wage is calculated as follows: (monthly $\mathrm{MW} \times 14) / 12$.

${ }^{8}$ Specifically, the amount varied from $€ 625.58$ for a single-member household to $€ 959.70$ for a household with three or more members and at least one pensioner. Single-parent families receive an additional $€ 45$.
} 


\subsection{Family unit labour market availability}

All members belonging to an MIS family unit who are able to work must be registered in the public employment service and commit to being available to work. In addition, they must participate in activities that increase their employability as they sign an inclusion-oriented employment improvement agreement. However, although the spirit of the law is that every recipient should search actively for a job, only around $40 \%$ are observed to receive any interventions from the public employment service or activating interventions. We do not know what criteria the public employment service use to follow MIS recipients to monitor their activation, i.e. whether individuals are self-selected into different activities or there is some kind of compulsory participation.

\section{The data set and some descriptive statistics}

\subsection{The data set}

Our data set consists of monthly longitudinal information on the full universe of individuals who were registered with the Basque public employment service from February 2015 to January 2016. Data are collected on the last day of each month. Most of those registered are unemployed, but some may be employed and searching for another job. Their employment status is clearly stated. In concrete, all MIS recipients must register with the Basque public employment service as a requisite for receiving income aid, independently of their employment status. For these reasons, this database is particularly suitable for the current analyses.

This rich database includes all the information provided by each individual when registering at the employment office, including standard demographic characteristics (gender, age, verified education level, nationality, postcode and residence, knowledge of other languages), as well as labour market information (previous employment experience, occupational and geographical searches, accurate unemployment duration, etc.). The Basque public employment service also provides exact information on whether individuals receive or have received unemployment benefits (entitled benefits, assistance benefits and/or MIS) and on the duration of entitlement. MIS recipients are captured from this information. Finally, the database also records information on the assistance measures from the public employment services that every unemployed worker has received in the last 12 years to enhance job access. Information such as the type of measure, number of hours and start and end dates is provided. Unfortunately, the data set does not contain information regarding income level or number of properties.

Basque public employment service divides the pool of unemployed workers on their files into "registered unemployed" and "other unemployed workers". The latter category, which accounts for around $22 \%$ of all unemployed workers, includes those not immediately available for work, those registered in the current month, those who just seek particular kinds of work such as outwork and teleworking and those who seek work for under $20 \mathrm{~h}$ a week. Students are also included in this category. We 
restrict our analysis to the "registered unemployed", i.e. those without a job who are seeking work and immediately available for any "regular" job.

For the period under study, the Basque Country has records of around 60.000 MIS recipients each month; among them, approximately 13.000 are employed and 38.000 are registered unemployed in the period under analysis, equivalent to $25 \%$ of all those registered as unemployed in the Basque Country.

\subsection{Statistical distribution of MIS recipients versus non-MIS recipients}

To provide a more precise picture of the differences between MIS recipients and other workers registered as unemployed, we present the distribution of each of the two groups under a total of four characteristics: gender, age $(<30,30-44$ and $>44)$, education level (primary at most, secondary and higher education) and duration of unemployment ( $<3$ months, 3-6 months, 6-12 months, 12-24 and > 24 months). Figures 1 and 2 show the distribution of MIS and non-MIS recipients, respectively, across the four characteristics. We do this for a particular month-October 2015- to get a better idea in not only relative but also absolute terms. Any other month from the sample would give almost identical patterns.

At first sight, the profile for education level and unemployment duration of MIS recipients is quite different from that of the rest of the unemployed. This is not surprising given that MIS is seen as a last resort scheme. In particular, 60\% of MIS recipients have no secondary education qualifications and more than half have spent more than 2 years unemployed. The equivalent figures are barely one third and one fourth, respectively, for non-MIS recipients. More precisely, the biggest group among recipients is that of the very long term unemployed aged over 30 with only primary education. This group accounts for a third of all MIS recipients. Among non-MIS recipients, the equivalent group accounts for barely $10 \%$. Furthermore, regardless of education level, MIS recipients over 30 who have spent more than 2 years looking for a job account for $50 \%$. Focusing on the youngest group, it can be seen that more than half have spent more than 2 years seeking employment and $70 \%$ have only primary education. However, the pattern is very different among those who do not receive MIS: those who have been unemployed for a very short time are generally young people with secondary or higher education. It is important to note that many young people with higher education continue studying if they do not find a job and are not therefore considered as unemployed. This behaviour is not found among unemployed people with lower education levels, who are precisely the most common group among MIS recipients.

\subsection{Monthly exit rates from unemployment to employment (job-finding rates)}

We now describe the patterns of monthly job-finding rates for recipients and nonrecipients of MIS, making use of the longitudinal nature of our data set. We define "exit into employment" as a transition from "registered unemployed" in the current 
month to a labour status of "employed" in the next month. ${ }^{9}$ Therefore, the characteristics of the unemployed people are fixed in the current month. Following the same structure as above, we characterise job-finding rates by comparing recipients with non-recipients of MIS using the same four characteristics, i.e. gender, age, education level and unemployment duration. Given that we observe unemployed people from February 2015 to January 2016, we can compute job-finding rates from March 2015 to January 2016.

On average, the monthly job-finding rate for MIS recipients is $3 \%$. This is significantly lower than the rate for non-MIS recipients, which is $9 \%$. Figures 3 and 4 show job-finding rates for MIS and non-MIS recipients, respectively, for different profiles. It is immediately apparent that job-finding rates increase with education level and strongly decrease with unemployment duration for both groups. To give some numbers on the strong negative association between unemployment duration and job-finding rates, Figs. 3 and 4 show that individuals unemployed for less than 3 months have an average exit rate of $11 \%$, while the very long term unemployed (over 2 years) have a rate of only 1\%. Interestingly, 60\% of MIS recipients belong to the group of very long term unemployed. Another point to note is that although education level is relevant to understanding differences in access to jobs, it is far less significant than unemployment duration: the exit rate of MIS recipients with higher education averages $5 \%$, compared to $2 \%$ among those with primary education only.

Figure 4 focuses on the comparison between MIS recipients and non-MIS recipients on job-finding rates. As mentioned above, there is a difference of 6 percentage points on average between the job-finding rates of the two groups. However, that difference varies markedly depending on individual profiles. For example, among the very short term unemployed, there is a difference of 7.5 points, while among the very long term unemployed the difference is barely one percentage point.

\subsection{Determinants of the probability of finding a job: MIS recipients versus non-recipients}

Finally, we estimate the probability of finding a job by the last day of each month for all those registered unemployed on the last day of the previous month. As above, we calculate the probability of finding a job from March 2015 to January 2016. The dependent variable, therefore, takes a value of 1 if the unemployed person gets a job in the consecutive month, and 0 otherwise.

To perform this exercise, we take into account all observable variables that may affect the employability of people registered with the public employment service. In particular, we include demographic characteristics such as sex, age, nationality, disability, education and language skills; job characteristics such as requested occupations, experience, activity in the previous field of work, unemployment duration, geographical scope of the new job search and month(s) in which the individual is observed as unemployed and province of registration.

\footnotetext{
9 The Basque Public Employment Service recodes any change in labour market status but contrary to other regional PES, those who find a job are not removed from the data set, which allows us to capture entries into employment.
} 

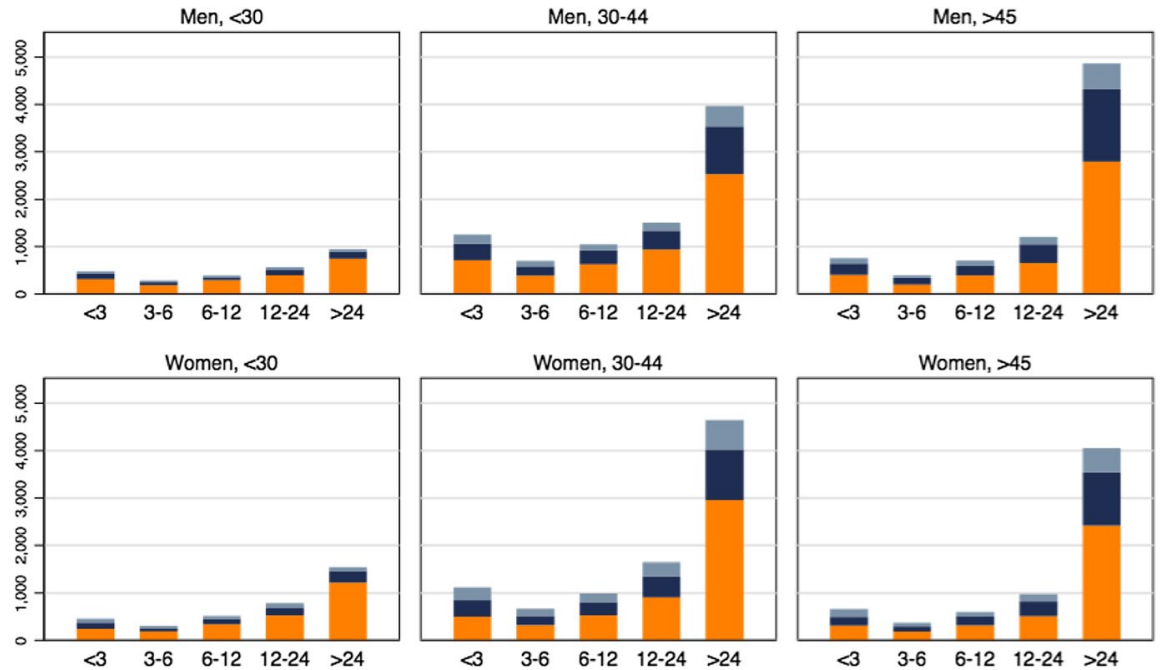

Primary

Secondary

Tertiary

Fig. 1 Unemployed MIS recipients in the Basque Country, October 2015. Axes: gender, age, unemployment duration (months), educational level. Source: Own elaboration. Lanbide microdata

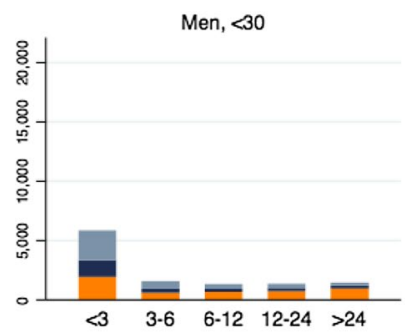

Men, 30-44

Men, $>45$
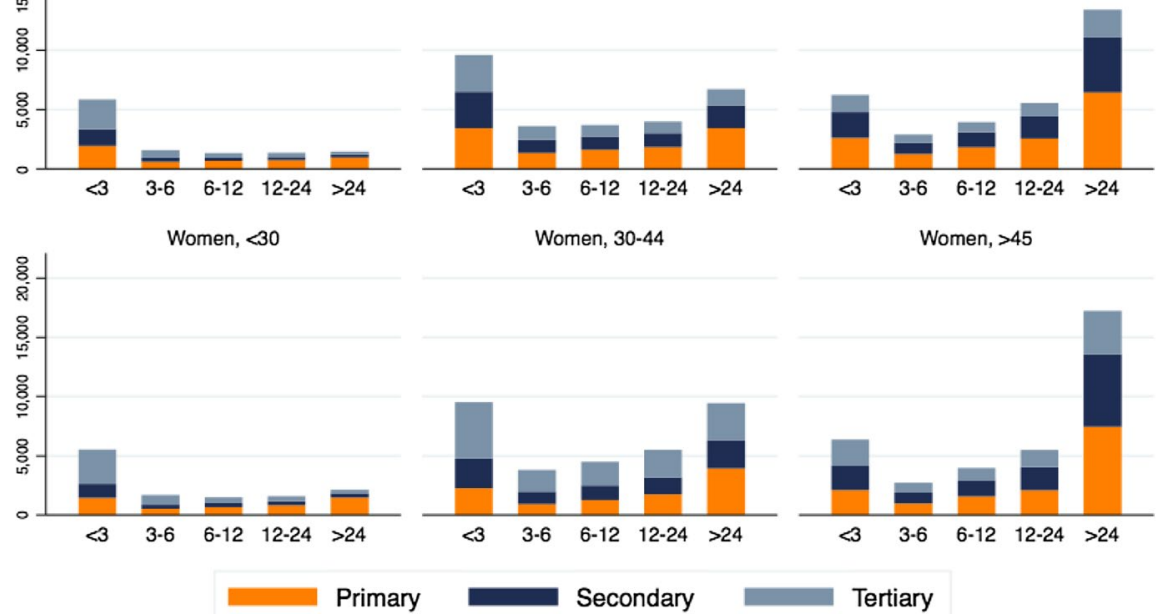

Women, 30-44

Women, >45

Fig. 2 Unemployed non-MIS recipients in the Basque Country, October 2015. Axes: gender, age, unemployment duration (months), educational level. Source: Own elaboration. Lanbide microdata 

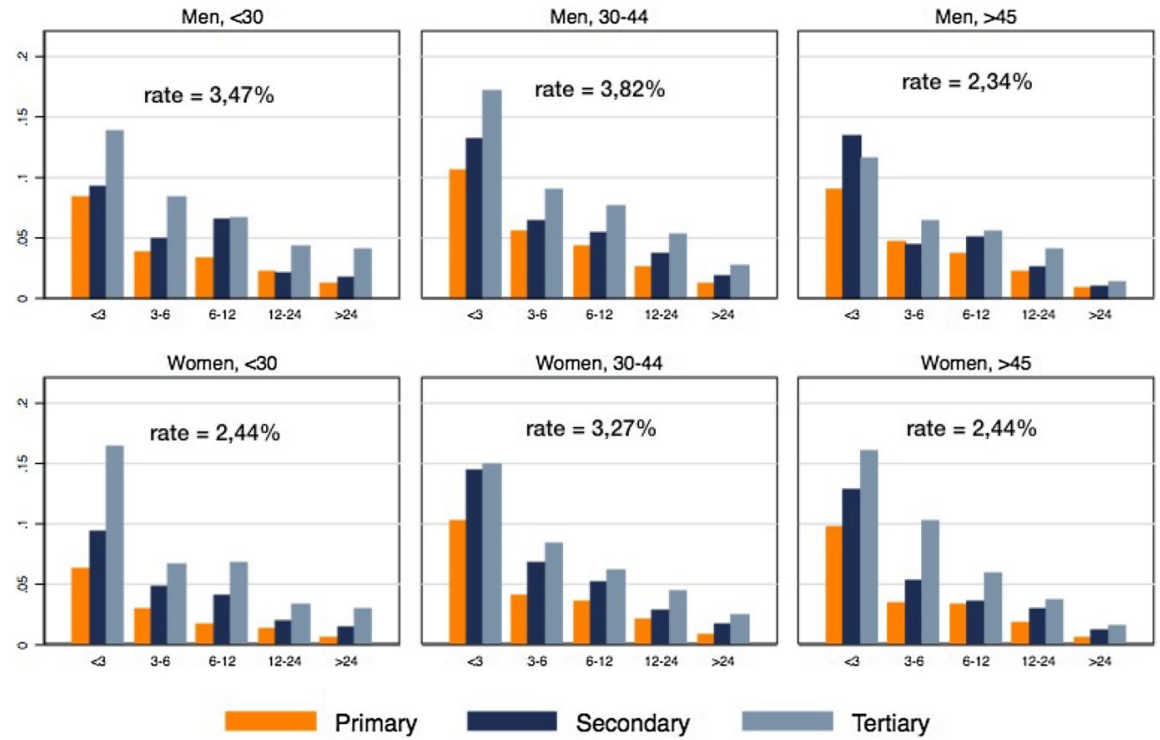

Primary

Secondary

Tertiary

Fig. 3 Exit rates in to the labour market of MIP perceivers in Basque Country, 2015. Axes: gender, age, unemployment duration (months), educational level. Source: Own elaboration. Lanbide microdata
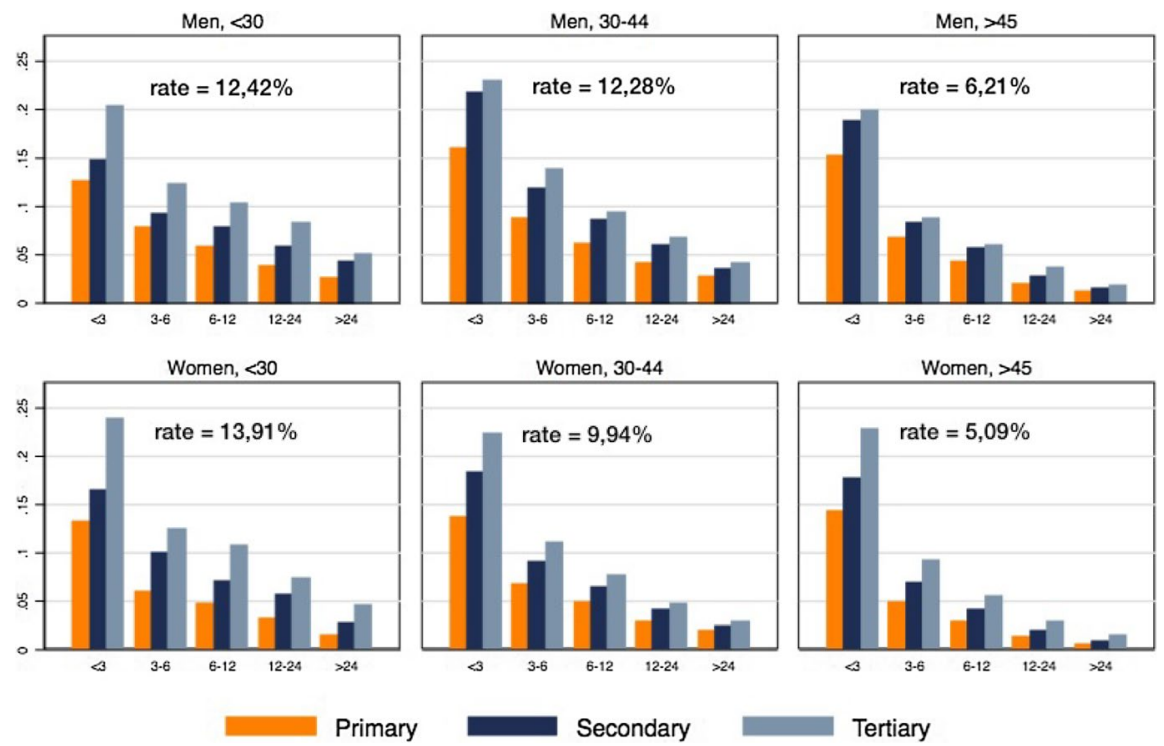

Primary

Secondary

Tertiary

Fig. 4 Exit rates in to the labour market of non-MIP perceivers in Basque Country, 2015. Axes: gender, age, unemployment duration (months), educational level. Source: Own elaboration. Lanbide microdata 
Table 1 Probability of finding a job

\begin{tabular}{|c|c|c|}
\hline & \multicolumn{2}{|c|}{ Dependent variable: exit probability } \\
\hline & Unemployed MIS recipients & Unemployed non-MIS recipients \\
\hline Women & $\begin{array}{l}-0.0008 \\
(0.00067)\end{array}$ & $\begin{array}{l}-0.0014 * * \\
(.0006315)\end{array}$ \\
\hline Foreign nationals & $\begin{array}{l}0.0002 \\
(0.00076)\end{array}$ & $\begin{array}{l}-0.0106^{* *} \\
(0.00107)\end{array}$ \\
\hline Disabled persons & $\begin{array}{l}-0.0074 * * * \\
(0.00197)\end{array}$ & $\begin{array}{l}-0.0173 * * * \\
(0.00243)\end{array}$ \\
\hline Social services derivation & $\begin{array}{l}-0.0227 * * * \\
(0.00505)\end{array}$ & $\begin{array}{l}-0.0554 * * * \\
(0.01238)\end{array}$ \\
\hline \multicolumn{3}{|l|}{ Benefits } \\
\hline Contributory & $\begin{array}{l}0.0104 * * * \\
(0.00151)\end{array}$ & $\begin{array}{l}0.0292 * * * \\
(0.00089)\end{array}$ \\
\hline Attendance & $\begin{array}{l}0.0091 * * * \\
(0.00080)\end{array}$ & $\begin{array}{l}0.0245 * * \\
(0.00112)\end{array}$ \\
\hline Ex-contributory & $\begin{array}{l}- \\
- \\
-\end{array}$ & $\begin{array}{l}0.0406 * * * \\
(0.00090)\end{array}$ \\
\hline Ex-attendance & $\begin{array}{l}- \\
- \\
-\end{array}$ & $\begin{array}{l}0.0207 * * * \\
(0.00105)\end{array}$ \\
\hline \multicolumn{3}{|l|}{ Activation services } \\
\hline Guidance & $\begin{array}{l}0.0056 * * * \\
(0.00056)\end{array}$ & $\begin{array}{l}0.0054 * * * \\
(0.00082)\end{array}$ \\
\hline Monitoring & $\begin{array}{l}0.0068 * * * \\
(0.00176)\end{array}$ & $\begin{array}{l}0.0048 \\
(0.00504)\end{array}$ \\
\hline Self-employment info & $\begin{array}{l}0.0164 * * * \\
(0.00358)\end{array}$ & $\begin{array}{l}0.0237 * * * \\
(0.00426)\end{array}$ \\
\hline Training & $\begin{array}{l}0.0195 * * * \\
(0.00126)\end{array}$ & $\begin{array}{l}0.0403 * * * \\
(0.000148)\end{array}$ \\
\hline \multicolumn{3}{|l|}{ Age } \\
\hline $25-30$ & $\begin{array}{l}0.0018 \\
(0.00151)\end{array}$ & $\begin{array}{l}0.0001 \\
(0.00152)\end{array}$ \\
\hline $30-35$ & $\begin{array}{l}0.0022 \\
(0.0015)\end{array}$ & $\begin{array}{l}-0.0144 * * * \\
(0.00154)\end{array}$ \\
\hline $35-40$ & $\begin{array}{l}0.0012 \\
(0.00144)\end{array}$ & $\begin{array}{l}-0.0206 * * * \\
(0.00153)\end{array}$ \\
\hline $40-45$ & $\begin{array}{l}0.0015 \\
(0.00146)\end{array}$ & $\begin{array}{l}-0.0200 * * * \\
(0.00154)\end{array}$ \\
\hline $45-50$ & $\begin{array}{l}-0.0006 \\
(0.00148)\end{array}$ & $\begin{array}{l}-0.0208 * * * \\
(0.00156)\end{array}$ \\
\hline $50-55$ & $\begin{array}{l}-0.0028^{*} \\
(0.00153)\end{array}$ & $\begin{array}{l}0.0265^{*} \\
(0.00158)\end{array}$ \\
\hline $55-60$ & $\begin{array}{l}-0.0083 * * * \\
(0.00159)\end{array}$ & $\begin{array}{l}-0.0473 * * * \\
(0.00159)\end{array}$ \\
\hline
\end{tabular}


Table 1 (continued)

\begin{tabular}{|c|c|c|}
\hline & \multicolumn{2}{|c|}{ Dependent variable: exit probability } \\
\hline & Unemployed MIS recipients & Unemployed non-MIS recipients \\
\hline $60-65$ & $\begin{array}{l}-0.0178^{* * *} \\
(0.00166)\end{array}$ & $\begin{array}{l}-0.0785^{* * *} \\
(0.00159)\end{array}$ \\
\hline \multicolumn{3}{|l|}{ Education } \\
\hline Primary & $\begin{array}{l}0.0026 * * * \\
(0.00098)\end{array}$ & $\begin{array}{l}0.0025^{*} \\
(0.00144)\end{array}$ \\
\hline Uncompleted secondary & $\begin{array}{l}0.0001 \\
(0.00095)\end{array}$ & $\begin{array}{l}0.0041 * * * \\
(0.00141)\end{array}$ \\
\hline Secondary & $\begin{array}{l}0.0053 * * * \\
(0.00102)\end{array}$ & $\begin{array}{l}0.0151 \\
(0.00140)\end{array}$ \\
\hline High school & $\begin{array}{l}0.0080 * * * \\
(0.00135)\end{array}$ & $\begin{array}{l}0.0157 * * * \\
(0.00155)\end{array}$ \\
\hline Medium-level vocational training & $\begin{array}{l}0.0111 * * * \\
(0.00148)\end{array}$ & $\begin{array}{l}0.0289 * * * \\
(0.00158)\end{array}$ \\
\hline High-level vocational training & $\begin{array}{l}0.0175 * * * \\
(0.00177)\end{array}$ & $\begin{array}{l}0.0284 * * * \\
(0.00158)\end{array}$ \\
\hline Undergraduate & $\begin{array}{l}0.0253 * * * \\
(0.00317)\end{array}$ & $\begin{array}{l}0.0301 * * * \\
(0.00187)\end{array}$ \\
\hline Bachelor's degree or higher & $\begin{array}{l}0.0176 * * * \\
(0.00230)\end{array}$ & $\begin{array}{l}0.0300 * * * \\
(0.00170)\end{array}$ \\
\hline \multicolumn{3}{|l|}{ Unemployment duration } \\
\hline $3-6$ months & $\begin{array}{l}-0.0524 * * * \\
(0.00189)\end{array}$ & $\begin{array}{l}-0.0796^{* * * *} \\
(0.00091)\end{array}$ \\
\hline $6-12$ months & $\begin{array}{l}-0.0662 * * * \\
(0.00172)\end{array}$ & $\begin{array}{l}-0.1045 * * * \\
(0.00087)\end{array}$ \\
\hline $1-2$ years & $\begin{array}{l}-0.0819 * * * \\
(0.00163)\end{array}$ & $\begin{array}{l}-0.1297 * * * \\
(0.00084)\end{array}$ \\
\hline $2-3$ years & $\begin{array}{l}-0.0857 * * * \\
(0.00164)\end{array}$ & $\begin{array}{l}-0.1392 * * * \\
(0.00091)\end{array}$ \\
\hline $3-4$ years & $\begin{array}{l}-0.0891 * * * \\
(0.00164)\end{array}$ & $\begin{array}{l}-0.1480 * * * \\
(0.00092)\end{array}$ \\
\hline 4 years or more & $\begin{array}{l}-0.0943 * * * \\
(0.00160)\end{array}$ & $\begin{array}{l}-0.1566 * * * \\
(0.00081)\end{array}$ \\
\hline Baseline prob. & 0.0291 & 0.0617 \\
\hline Average pred. prob. & 0.0304 & 0.0750 \\
\hline Observations & 431,773 & $1,297,683$ \\
\hline
\end{tabular}

Robust standard errors in parentheses $* * * p<0.01, * * p<0.05, * p<0.1$

Additional variables are included in the estimation: experience in requested occupations, activity in previous field of work, language skills, geographical scope of job search, province of registration and months in which the individual is observed as unemployed

Baseline profile: men, native, no disabilities, not referred to social services, under 25 , illiterate, unemployed for less than 3 months 
We add a dummy indicating whether individuals have ever been referred to social services. The receipt of benefits in the current or in previous months is also included. We include in our estimation an indicator for whether individuals have received activation services at least once in the last 6 months. On average, $40.7 \%$ of MIS recipients have received some kind of measure in the last 6 months, as compared to $13.75 \%$ of non-recipients. We divide activation service into the following categories: guidance, monitoring, information on self-employment and training.

Table 1 presents the results of the estimation (marginal effects are reported) using a pooled probit model with month and province fixed effects. ${ }^{10}$ The first column estimates the probability of finding a job for MIS recipients, and the second does likewise for non-recipients. Note that this estimation does not account for unobserved heterogeneity. It should be taken as a preliminary view of the importance of the characteristics of unemployed people in the job search process.

The most noteworthy result has been already anticipated: unemployment duration is the strongest predictor of the probability of exiting unemployment. The chances of entering employment decrease dramatically as the time for which a person remains unemployed increases. The largest decrease in the probability of getting a job occurs after the barrier of 3 months (reference group) with a reduction of 5 percentage points when individuals are unemployed for between 3 and 6 months. Being unemployed for between 6 months and 1 year is associated with one-point reduction (6.5 points less likely than for those unemployed for less than 3 months), and for those unemployed for between 1 and 2 years, the probability falls by 1.6 points ( 8 points less likely). The negative correlation increases to 9 points if the duration of unemployment is higher than 2 years.

Considering levels of studies, in general the likelihood of finding a job can be seen to be correlated with the education level of each unemployed individual: having secondary education qualifications (compared with primary or no education) increases the probability 0.5 p.p; completing high school increases it by 0.8 points; medium-level vocational training increases it by 1.2 points and higher-level vocational training and higher university degrees raise it by 1.9. Notice that the impact of being unemployed for more than 3 months is double that of having university studies (as compared to primary or no education) for MIS recipients.

Table 1 also presents an exploratory assessment of the relationship between job finding and activation services received by public employment services. Guidance, monitoring and training are positively correlated with job-finding probability. However, this cannot be interpreted as a causal effect. Indeed, a separate section below is dedicated exclusively to a counterfactual assessment of the impact of activation services on the probability of finding a job. Note that an activation measure such as information/guidance for self-employment has a clearly differentiated nature, since people who use it are practically on their way towards self-employment. Thus, measuring its effectiveness via its impact on the probability of leaving for a job does not make much sense. From now on, we will assess the effectiveness of only the other three interventions in exits into employment.

$\overline{10}$ Population average with a robust estimator of the variance is used. 


\section{Assessing the impact of the Basque minimum income scheme on the labour market: a counterfactual assessment}

Any minimum income scheme is by nature a passive policy, as its main aim is to guarantee all individuals the resources required to meet their minimum needs. However, as mentioned above, the Basque MIS, following the dictates of the European Council since 2008, requires recipients to participate (in principle) in active policies to make their entry into employment as fast and successful as possible. In view of this twofold scope of the MIS, with both passive and active aspects, our assessment of the policy is also twofold.

Firstly, although the goal of any passive policy is not to accelerate the employability of the unemployed but to supplement their income so as to alleviate poverty, empirical evidence generally finds that most income transfers to the unemployed result in a delay in job finding. Reservation wages increase for anyone who receives additional income, and this typically delays job entry, hence lowering job-finding rates. However, there are two aspects of the MIS which might accelerate rather than delay job access: one is that the MIS can also be received by employed workers with insufficient income to meet minimum needs, so MIS recipients might be willing to accept jobs with "low" wages compatible with retaining the transfer. The other is that recipients can lose their MIS if it is proved that they have rejected job offers. For these reasons, the typical "delay" effect of a passive transfer such as the MIS may be partially offset by some kind of "acceleration effect" for reasons other than the activation measures implemented.

Our first assessment with respect to the impact of the MIS in the Basque Country looks at whether the MIS causes a delay or an acceleration effect, and if so on what scale. This is the first objective addressed in this section.

Secondly, and perhaps more interestingly, we seek to assess whether active policies offered to MIS recipients make for better transitions towards employment. This is the second objective of the section.

\subsection{Empirical assessment strategy}

In both analyses, the aim is to assess the impact either of the MIS itself or of the activation measures aimed at MIS recipients on the probability of exiting unemployment. As in previous estimations, the dependent variable $(Y)$ takes a value of 1 if the unemployed individual gets a job in the next month and 0 otherwise. The treatment $(D)$, which is a dummy variable, takes a value of 1 firstly when the individual is an MIS recipient and secondly if the individual receives activation measures. ${ }^{11}$ The covariates included in our analyses are the same as in previous estimations $(X)$.

The main problem that we face in both the analyses carried out in this paper is sample selection. In the first one, unemployed people need to comply with strict requirements to receive MIS. In the second analysis, the profile of the unemployed

\footnotetext{
11 We are unable to draw up a duration analysis because of data limitations. Our data set includes only 2015 information, and for MIS beneficiaries (more than 70\% of whom have been unemployed for more than 1 year), we would need longer longitudinal information.
} 
people who receive activation measures differs broadly from that of non-activation measures recipients (as shown below). Consequently, given that individuals are not randomly chosen, a mean difference between the outcomes of treated and control group cannot be used to infer causality in the corresponding treatment. Only when participation in the treatment depends on observable characteristics (X) can the average treatment effect on the treated (ATT) be estimated by conditioning on these variables, rendering the counterfactual outcome independent of the treatment (conditional independence assumption, CIA). However, the probability of finding a job for recipients and non-recipients of MIS might be affected by confounding factors. Therefore, it is hard to justify the validity of CIA in this analysis. In the second analysis, our lack of understanding of the selection process for receiving activation measures means that we are unable to argue as to whether CIA is satisfied or not.

Propensity score methods are useful for estimating treatment effects using observational data since they enable observational studies to be designed along lines similar to randomised experiments (Rubin 2001). ${ }^{12}$ Rosenbaum and Rubin (1983) show that instead of conditioning on the covariates, conditioning on the probability of potential treatment conditional on observable covariates, the propensity score $(p(x)=P(D=1 / X))$, suffices to achieve a balance between the treatment and control groups as long as other requirements are met. Firstly, the covariates influencing assignment and outcome should not predict the treatment participation deterministically (weak overlap, $P(D=1 / X)<1$ for all $\mathrm{X}$ ). Secondly, the participation in the treatment of one individual must not have an impact on the outcome of other treated or control individuals. The second assumption might be quite strong. Indeed, Crépon et al. (2013) suggest that some activation policies could have a displacement effect as they cannot reject that the programme had, on net, no positive effect. We cannot test whether activation measures directed to MIS recipients lead to displacement effects, and so results should be taken cautiously when propensity score methods are used.

Different propensity score approaches have been suggested for estimating an adequate counterfactual outcome. The most widely used methods are matching and weighting (Imbens 2004). These methods seek to remove observed systematic differences between treated and control subjects. In our first analysis, inverse probability weighting (IPW) makes the distribution of observable covariates similar in the treated and control groups. ${ }^{13}$ Furthermore, as explained below, IPW is the only valid methodology in our first analysis due to the characteristics of the treatment. For the second part of our research, our lack of knowledge of the selection mechanism and

\footnotetext{
${ }^{12}$ Another alternative that has been suggested to us is the regression discontinuity approach, using as a control group those households that are close to fulfilling the total income requirements of the household to receive the MIS but do not comply. Unfortunately, this methodology cannot be used here for several reasons. Firstly, as previously mentioned, we do not have information on the total household income; therefore, we cannot measure how far individuals or households are to comply with the income requirement to receive MIS. Secondly, we are not able to identify those individuals belonging to the same household; thus, matching MIS households with non-MIS ones is not possible. Finally, other crucial household variables, such as the number of children or other dependents in the household, are not available either.

13 Table 2 shows the distribution of the characteristics in the weighted sample.
} 
the characteristics of the sample assessed leads us to calculate the treatment effect using two different methods: inverse probability weighting (IPW) and propensity score matching (PSM).

The idea behind inverse probability weighting is the following: random assignment guarantees that the distribution of the covariates among units of observation in the treatment and control groups is probabilistically equivalent, i.e. all units are equally likely to be in the treatment or control groups. However, when the assignment is not random, some individuals are more likely to be treated than others, depending on their particular characteristics. To account for these differences in the regression formulation, observations must be weighted according to the inverse probability of receiving treatment. This gives a pseudo-random sample by weighting observations by the inverse of the probability of being treated. Therefore, the distribution of covariates between the groups would be probabilistically equivalent (Gardeazabal and Vega Bayo 2016). In short, weighting individuals by the inverse probability of treatment creates a synthetic sample where treatment assignment is independent of the observed covariates. Inverse probability weighting enables unbiased estimates of average treatment effects to be obtained under the assumption that selection on the unobserved variables is the same as selection on the observed variables. This is a strong assumption, given that variables such as family income, which is unobserved, and perhaps other unobserved family characteristics could be related to some observable factors such as educational level or unemployment duration. In spite of weighting individuals on the base of all observed variables, we might not eliminate completely the unobserved differences between the weighted treated and control group. We devote a sub-section below to check for the sensitivity of results to non-compliance of this assumption.

The IPW estimator uses a two-step approach to estimate treatment effects. The specification for the average treatment effect on the treated (ATT) is as follows:

1. Estimate the probability of being treated based on the covariates by a probit ${ }^{14}$ regression. Denote $p_{i}(x)$, i.e. the propensity score. Use the inverse probability weights to compute the new pseudo-random sample. Build regression weights $\left(w_{i}\right)$ as:

$$
\begin{gathered}
w_{i}=1 \quad \text { if } \quad D_{i}=1 \\
w_{i}=\frac{p_{i}(x)}{1-p_{i}(x)} \quad \text { if } \quad D_{i}=0
\end{gathered}
$$

The idea behind this weighting procedure is quite straightforward. The objective is to approximate the distribution of the covariates of the control group to those of the treated group. For that reason, all treated individuals have weights of 1 . Control

${ }^{14}$ A logit model can be also used. 
individuals with a 0.5 probability of being MIS recipients are assigned a weight of 1 ; those with a probability higher than 0.5 have weights of more than 1 with an increasing pattern and those with a probability lower than 0.5 have weights of less than 1 with a decreasing pattern. By doing this, the outcome of those control individuals with the highest probabilities of being MIS recipients would gradually weigh more and the outcome of those control individuals with the lowest probability of being MIS recipients would weigh exponentially less.

2. Calculate the ATT of the new sample, i.e. run a probit regression of the outcome on a constant and the treatment using the weights calculated. The coefficient of the binary treatment in the previous regression is a consistent estimation of ATT, provided that the propensity score is correctly specified. Adding all covariates as additional regressors leads to the augmented inverse probability weighting (AIPW) estimator. Results from both estimators will be presented.

In the second assessment, an additional propensity score approach is applied: propensity score matching (PSM) here helps us also to estimate the impact of activation measures. This methodology entails matched sets of treated and untreated subjects who share similar propensity scores (Rosenbaum and Rubin 1985), and it enables the ATT to be estimated (Imbens 2004). The most common implementation is one-to-one pair matching, in which pairs of treated and controls are formed in such a way that they have similar propensity scores. Once a matched sample has been formed, the treatment effect can be estimated by directly comparing outcomes between matched treated and control individuals. Schafer and Kang (2008) suggest that treated and control subjects should be regarded as independent within matched samples. By contrast, Austin (2011) argues that the propensity score matched sample does not consist of independent observations. He maintains that in the presence of confounding factors covariates are related to outcomes, so matched subjects are more likely to have similar outcomes than randomly selected subjects.

Based on Austin's argument, we reject the use of the propensity score matching in the first analysis. Non-observed factors such as family income differ systematically between the treated and control individuals as they are crucial determinants for being selected for the treatment. However, the second assessment uses PSM, as we find it reasonable to argue that the unobservable factors of treated and control individuals resemble each other more (given the selected control group used) than in the first analysis.

\subsection{Impact of MIS on job-finding rates-does MIS reduce the probability of finding a job?}

As shown in previous sections, MIS recipients have a monthly job-finding rate of $3 \%$, compared to $9 \%$ for the non-MIS unemployed group. However, as already stated, the composition of the group of MIS recipients differs notably from that of the rest of the unemployed, and those differences (mainly longer unemployment duration and lower education level) may be causing at least part of the differences 
observed in job-finding rates. To isolate compositional differences from the scheme, we use the inverse probability weighting methodology as detailed above. This enables us to assess the extent to which the difference observed in job-finding rates is explained by (1) compositional differences between the two groups and (2) by the MIS.

To that end, we include in the treatment group all those individuals who are recipients of the MIS in the current month. Given that the observation unit is one individual per month, an individual may belong to the treatment group in some months (in which he/she receives the MIS) but not in others (in which he/she does not receive it). To set up an adequate counterfactual, we must define the control group so that it provides the best possible simulation of job-finding rates for the group of MIS recipients had they not received the benefit. According to the data, for 93\% of MIS recipients MIS is the ONLY income aid received; a further $6 \%$ also receive other welfare benefits and the remaining $1 \%$ receive contributory benefits. In the last two situations, they receive both types of income aid because the other benefits received are still lower than what it is considered necessary to meet basic household needs. We think that it makes sense to assume that if the income scheme did not exist the $93 \%$ currently receiving only MIS would not be getting any additional income aid and the remaining 7\% would receive an insufficient amount. For this reason, we have chosen to include unemployed individuals who do not receive ANY benefit in the current month in the control group. ${ }^{15}$ For this group, the observed monthly job-finding rate is $6.5 \%$. Consequently, the outcome of the assessment must be interpreted as the differential impact of MIS on the job-finding rate compared to not receiving any benefit.

However, the treatment (receiving MIS) is by no means random. As specified above, there are specific requirements to be complained with in order to receive it. Some of them are observable in our data set, but others are non-observed variables, such as total household income. To "correct" for these differences between the treatment and control groups, we use the inverse probability weighting method. ${ }^{16}$

Table 2 presents the distribution of the weighted control group, which shows that the differences in the main characteristics are eliminated by using the weighting procedure.

The results of the inverse probability weighting estimation and of its extended version (augmented inverse probability weighting) are presented in Table 3 . It can be seen that the impact of MIS is not significantly different from zero at any significance level. The result is the same for both the IPW and the AIPW estimators, which makes it more reliable. ${ }^{17}$ This indicates that the monthly job-finding probability for MIS recipients would have been the same if they had not received any benefit. We

\footnotetext{
15 In October 2015, the fraction of unemployed individuals who did not receive ANY benefit in the Basque Country amounted to $65 \%$ of total unemployed workers.

16 As noted in the methodological section, we are imposing the assumption that once the observed variables are weighted for, there are not significant differences between the treated and control group in unobserved variables, assumption that will be tested below.

17 The assessment is also conducted using the propensity score matching methodology. However, the results are divergent, corroborating the argument of Austin (2011).
} 
can thus conclude that the MIS itself does not reduce the probability of finding a job. In other words, the differences observed in job-finding rates between the treatment and the control group are due solely to the difference in the composition of the two groups and not to the effect of the policy.

As a second step, we analyse whether the MIS has different impacts on different demographic groups. Specifically, we assess the impact of MIS on men and women separately, on three age groups $(<30,30-44$ and $>45)$ and on three education groups (primary, secondary and higher). ${ }^{18}$ The results, presented in Table 4, confirm that the impact of MIS is not homogeneous across demographic groups. In particular, for women MIS delays exit to employment slightly (0.2 p.p), whereas it has no impact on men. According to the legislation, all members of the family MIS recipients must be registered in the public employment service as unemployed. It may be the case that some women belonging to those households and registered as unemployed are actually inactive because of the traditional gender role attitudes. This would lead into an apparent delay of MIS beneficiaries women compared to nonMIS women. Second, the MIS accelerates job finding for older workers (0.2 p.p), whereas for young workers $(<30)$ it delays exit to employment $(1$ p.p). This delay among young individuals is also found by Salehi-Isfahani and Mostafavi-Dehzooei (2018). They justify the delay as a result of an extension in the educational period, which contributes to increase educational attainment among the youth. Finally, we find a delay as an impact of MIS for less educated workers (0.2 p.p), whereas it accelerates job entry for those with more than primary education $(0.2$ p.p for workers with secondary education and 0.5 p.p for those with higher education). As a possible explanation, MIS beneficiaries cannot reject job offers and it may be the case that medium or high-educated perceivers accept job offers that a non-MIS perceiver would not accept, in order not to lose the aid.

Our results coincide partially with the ex-ante assessment in Clavet et al. (2013) and with the findings (double and triple difference estimation strategy) in Chemin and Wasmer (2012). Both find a negative impact on labour market participation, particularly among specific groups such as low-skilled workers. However, their results are not directly comparable to ours as the methodology and the design of the policies in the regions that they examine are different. To our knowledge, there is no comparable assessment of a similar policy.

\subsection{Robustness check of the impact of MIS on job-finding probability}

The assumption we have imposed for the former analysis is that "selection on the unobserved variables is the same as selection on the observed variables". Under such assumption, once selection onto observables is controlled for, the estimated impact should not be biased due to unobserved variables. However, such assumption is rather strong, particularly in our case, where household income is unobserved and it is a key to determine whether to be an MIS recipient or not. It is plausible

\footnotetext{
18 The same analysis is not carried out for duration of unemployment because of the endogeneity of the variable.
} 
Table 2 Composition of the treated, non-weighted and weighted control groups in the analysis of the impact of MIS on the probability of finding a job (\%)

\begin{tabular}{|c|c|c|c|}
\hline & Treatment & Non-weighted control & Weighted control \\
\hline \multicolumn{4}{|l|}{ Gender } \\
\hline Men & $\begin{array}{l}49.6 \\
(0.498993)\end{array}$ & $\begin{array}{l}42.19 \\
(0.4951418)\end{array}$ & $\begin{array}{l}48.3 \\
(0.4844159)\end{array}$ \\
\hline Women & $\begin{array}{l}50.4 \\
(0.498993)\end{array}$ & $\begin{array}{l}57.81 \\
(0.4951418)\end{array}$ & $\begin{array}{l}51.7 \\
(0.5155841)\end{array}$ \\
\hline \multicolumn{4}{|l|}{ Age } \\
\hline$<30$ & $\begin{array}{l}16.27 \\
(0.3753089)\end{array}$ & $\begin{array}{l}20.13 \\
(0.4050923)\end{array}$ & $\begin{array}{l}14.1 \\
(0.3587106)\end{array}$ \\
\hline $30-44$ & $\begin{array}{l}45.73 \\
(0.4985333)\end{array}$ & $\begin{array}{l}39.32 \\
(0.489773)\end{array}$ & $\begin{array}{l}50.5 \\
(0.4999876)\end{array}$ \\
\hline$>44$ & $\begin{array}{l}37.99 \\
(0.4824372)\end{array}$ & $\begin{array}{l}40.55 \\
(0.4885698)\end{array}$ & $\begin{array}{l}35.4 \\
(0.4752678)\end{array}$ \\
\hline \multicolumn{4}{|l|}{ Education } \\
\hline Primary & $\begin{array}{l}59.82 \\
(0.4948926)\end{array}$ & $\begin{array}{l}32.7 \\
(0.4681706)\end{array}$ & $\begin{array}{l}61.3 \\
(0.4877771)\end{array}$ \\
\hline Secondary & $\begin{array}{l}26.83 \\
(0.4500403)\end{array}$ & $\begin{array}{l}29.72 \\
(0.4586649)\end{array}$ & $\begin{array}{l}26.3 \\
(0.4403324)\end{array}$ \\
\hline Tertiary & $\begin{array}{l}13.35 \\
(0.3536833)\end{array}$ & $\begin{array}{l}37.58 \\
(0.4840227)\end{array}$ & $\begin{array}{l}12.4 \\
(0.3329607)\end{array}$ \\
\hline \multicolumn{4}{|c|}{ Unemployment duration } \\
\hline$<3$ months & $\begin{array}{l}12.29 \\
(0.3062342)\end{array}$ & $\begin{array}{l}33.73 \\
(0.46045)\end{array}$ & $\begin{array}{l}11.5 \\
(0.3026258)\end{array}$ \\
\hline $3-6$ months & $\begin{array}{l}7.04 \\
(0.2656487)\end{array}$ & $\begin{array}{l}10.8 \\
(0.3307774)\end{array}$ & $\begin{array}{l}6.2 \\
(0.2641384)\end{array}$ \\
\hline $6-12$ months & $\begin{array}{l}11.03 \\
(0.3299325)\end{array}$ & $\begin{array}{l}11.98 \\
(0.3471036)\end{array}$ & $\begin{array}{l}11.3 \\
(0.3332849)\end{array}$ \\
\hline $1-2$ years & $\begin{array}{l}17.42 \\
(0.3843022)\end{array}$ & $\begin{array}{l}13.55 \\
(0.3424064)\end{array}$ & $\begin{array}{l}18.8 \\
(0.3920865)\end{array}$ \\
\hline$>2$ years & $\begin{array}{l}52.21 \\
(0.4997933)\end{array}$ & $\begin{array}{l}29.94 \\
(0.4556357)\end{array}$ & $\begin{array}{l}52.1 \\
(0.49997)\end{array}$ \\
\hline
\end{tabular}

Treated group: unemployed MIS recipients. Control group: unemployed people without benefits Standard errors in parenthesis

that even after controlling for observables by weighting the sample, unobserved factors between the treated and control group are not randomly distributed. If that were the case, our previous results would be biased. Hence, we present some sensitivity checks to test whether this is indeed the case.

Under the imposed assumption, once the weighted procedure has been implemented, we expect a non-significant correlation between the error term of the probability of being an MIS recipient (which contains potential unobserved variables, such as household income) (henceforth $u$ ) and the error term of the estimation of the 
Table 3 Assessment results: impact of MIS on the probability of finding a job

\begin{tabular}{lll}
\hline & IPW & AIPW \\
\hline ATT & 0.000135 & -0.000690 \\
& $(0.000823)$ & $(0.000510)$ \\
No. observations & 724,144 & 724,144 \\
Treated individual & 42,606 & 42,606 \\
Treated individual-month & 431,776 & 431,776 \\
Control individual & 55,487 & 55,487 \\
Control individual-month & 292,368 & 292,368 \\
\hline
\end{tabular}

Treated group: unemployed MIS recipients. Control group: unemployed people without benefits

$I P W$ inverse probability weighting, AIPW augmented inverse probability weighting

Robust standard errors in parentheses $* * * p<0.01, * * p<0.05$, $* p<0.1$

probability of finding a job (henceforth $\varepsilon$ ). Table $5 \mathrm{~A}$ shows that there is no correlation whatsoever between the two error terms.

Additionally, we check whether the probability of finding a job is directly affected by $u$, as such error term includes household income and other potential unobserved variables. Table 5B extends the AIPW estimation of Table 4 by including $u$ as an additional regressor. Neither the treatment nor $u$ is significant at any statistical level for the probability of finding a job, which reinforces the absence of bias of the results found above.

Finally, we provide a third sensitivity check developed by Altonji et al. (2005), henceforth AET, and more recently by Oster (2019). ${ }^{19}$ Intuitively, their approach consists on exploring the sensitivity of the ATT estimation to the correlation between the $\varepsilon$ and $u$. To do so, different correlation coefficients between them are imposed in order to test whether the ATT changes. Under the imposed assumption, the correlation between the two errors should be one $(\rho=1)$. For our particular case, this requires that the relation between the probability of finding a job and the observed variables has the same relationship with being an MIS recipient as the relation of the probability of finding a job and the unobserved variables.

Unfortunately, their methodology is applicable only for linear models. Hence, before doing the sensitivity check, we re-estimate the ATT with a linear probability model, instead of the previous probit estimation. This is depicted in Table 5C and reveals, as before, no impact of MIS on the probability of finding a job. Finally, we re-estimate the ATT impact (with a linear probability model) imposing, as AET, three different correlation coefficients between $\varepsilon$ and $u$, in particular (1) $\rho=0$, (2) $\rho=0.2$, (3) $\rho=0.5$.

Results are shown in Table 5D and confirm that the ATT estimate does not depend on the correlation between the two errors. This means even if the relation

19 For a detailed explanation of the check, see Altonji et al (2005). 


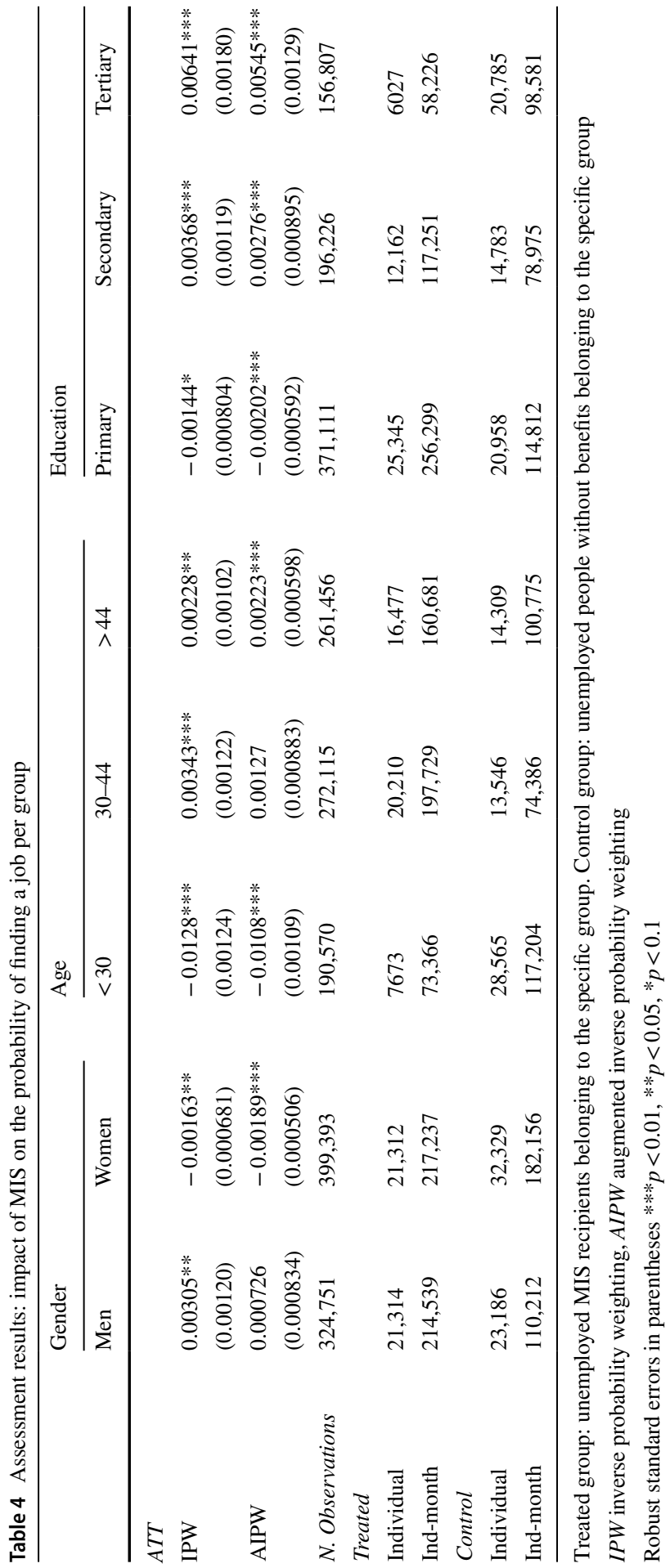


Table 5 Robustness check: impact of MIS on the probability of finding a job

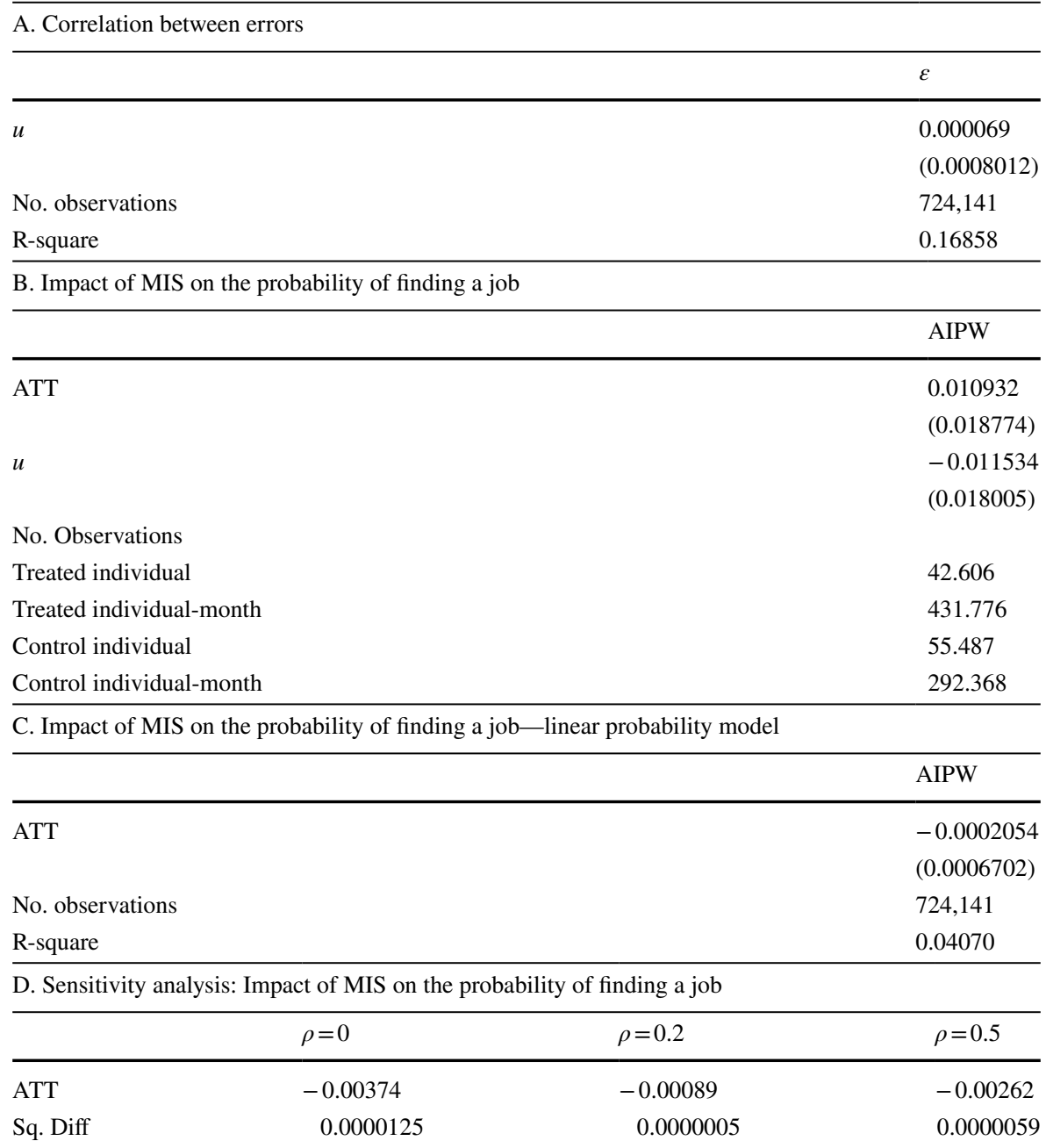

Treated group: unemployed MIS recipients. Control group: unemployed people without benefits $A I P W$ augmented inverse probability weighting

Robust standard errors in parentheses $* * * p<0.01, * * p<0.05, * p<0.1$

between the probability of finding a job and the observed variables has not the same relationship with being an MIS recipient as the relation of the probability of finding a job and the unobserved variables, our previous results remain.

The three sensitivity checks developed in this sub-section reinforce the finding that on average there is no impact of MIS on exiting into a job. This result holds even if there are unobserved variables that are correlated with the treatment and potentially with the outcome. The IPW methodology, thus, seems to be adequate to control for potential biases due to unobserved variables for this particular exercise. 
The main conclusion of this exercise is as follows: while Gorjón (2017) finds that the Basque MIS is very effective at the time of reducing the intensity and the severity of poverty, our analysis leads us to conclude that on average the MIS per se does not delay exit to employment. However, we do find differences in its impact on different demographic groups. In particular, it causes an undesired delay effect (also commonly found in other passive policies) for women, the less educated and young people, but accelerates entry into employment for medium and high-educated workers and for those aged over 45.

\subsection{The impact of active policies on job-finding probability for MIS recipients}

In this section, we assess the effectiveness of the activation interventions received by MIS recipients. Such an assessment is highly recommended given that in general active policies are quite costly. It enables us to check and if necessary modify and improve the efficiency of the Basque public employment service in providing recipients with the tools that they need to enter employment. This information can certainly highlight what actions should be strengthened, modified or even eliminated.

As mentioned before, we focus on three types of active policy: guidance, monitoring and training. Individuals are classed as users of activation services if they are observed to have received such measures at least once in the last 6 months (including the current month).

First, we present some descriptive statistics to show the extent of activation for the MIS group. As in the descriptive section, we focus (in order to present the characteristics of the unemployed) on a particular month (October 2015) so as to avoid overrepresentation of the long-term unemployed. Of the 38.345 unemployed people registered as MIS recipients in that month, 15.630 had received some kind of active policy in the form of guidance, monitoring or training at some time in the previous 6 months. This amounts to $40.8 \%$ of the total. As regards the types of services received, 15,106 people (39.4\% of all unemployed MIS recipients) received guidance services, $265(0.7 \%)$ monitoring services and 881 (2.3\%) training courses. This means that 728 individuals received more than one type of service. Given the low figure for monitoring, from here on we focus our results on activation through guidance or training interventions.

A brief profile is given below of how individuals involved in each of these two policies compare to individuals who receive no activation measures. Table 6 presents the distribution of the four main characteristics (sex, age, education and unemployment duration) depending on the type of active policy received.

In general, men receive more activation than women: around $65 \%$ of those who received training were men. The age range varies depending on the type of service. Guidance and training predominate in the 30-45 age range (their relative incidence among MIS receivers is 46\%). In general, young people tend to receive fewer activation interventions. There are also substantial differences between education levels: $60 \%$ of MIS recipients have at most primary education, $27 \%$ secondary and $13 \%$ higher education, which means that on average fewer activation measures 
are received by highly educated MIS recipients. In addition, activation measures decrease as unemployment duration increases.

Furthermore, we find distributional differences per type of activation measure. Guidance measures are distributed similarly across education levels, but we find significant differences in training measures, as recipients with secondary or higher education levels receive more training measures than those with at most primary education.

To assess the impact of each of these activation interventions, we place those MIS recipients who have received each particular activation policy being assessed (either individual guidance or training) in the last 6 months in the treatment group. As before, we measure the impact of receiving the activation measures on monthly job-finding rates. As a control group, we use MIS recipients who have not participated in ANY activation measures from the public employment service in the last 6 months so as to get a cleaner impact of each specific activation measure. ${ }^{20}$ The results must therefore be interpreted as the impact of the intervention on the probability of finding a job compared to not receiving any activation service in the last 6 months.

As shown in Table 6, the treatment and control groups differ in important characteristics such as the duration of unemployment and education level. We assess each intervention following the IPW methodology described above. The interventions are thus "pseudo-randomised", so the distribution of the covariates between the two groups is balanced and the treatment is probabilistically equivalent. Therefore, the impact of each type of intervention can be properly assessed without the results being biased by differences in composition.

In addition to the IPW (and AIPW) method, we also use a propensity score matching technique to enhance robustness. Given that the control group now consists of MIS recipients (although they do not receive activation measures), we find it reasonable to assume that unobserved confounding factors of treated and control individuals do not differ substantially from one group to the other. This assumption is essential to validate the use of the propensity score matching technique.

The results of the assessment of each active policy for MIS recipients (guidance and training) are shown in Table 7. Inverse probability weighting (IPW), augmented inverse probability weighting (AIPW) and the propensity score matching (PSM) ${ }^{21}$ estimators are presented. The first three columns correspond to the three specifications for the impact of guidance service. It can be seen that guidance has a positive impact on exit into employment. This impact is statistically significant for all three approaches, although its magnitude differs slightly from one to the other. As a general result, we conclude that guidance increases the probability of getting a job by

\footnotetext{
${ }^{20}$ As robustness check an alternative control group has been used, i.e. those who did not participate in any activation measures in the last year, the results show that the impact of both services is very similar or even more accentuated.

21 One-to-one pair matching implementation is presented. However, the results barely change when different numbers of matches per observation are used in both analyses.
} 
Table 6 Composition of MIS recipients per type of activation $(\%)$

\begin{tabular}{|c|c|c|c|}
\hline & No activation & Guidance & Training \\
\hline \multicolumn{4}{|l|}{ Gender } \\
\hline Men & $\begin{array}{l}48 \\
(0.4979134)\end{array}$ & $\begin{array}{l}51.7 \\
(0.4979134)\end{array}$ & $\begin{array}{l}64.5 \\
(0.4851443)\end{array}$ \\
\hline Women & $\begin{array}{l}52 \\
(0.4979134)\end{array}$ & $\begin{array}{l}48.3 \\
(0.499953)\end{array}$ & $\begin{array}{l}35.5 \\
(0.4851443)\end{array}$ \\
\hline \multicolumn{4}{|l|}{ Age } \\
\hline$<30$ & $\begin{array}{l}18.6 \\
(0.3845407)\end{array}$ & $\begin{array}{l}12.9 \\
(0.350857)\end{array}$ & $\begin{array}{l}16 \\
(0.3854633)\end{array}$ \\
\hline $30-44$ & $\begin{array}{l}43.1 \\
(0.4969012)\end{array}$ & $\begin{array}{l}49.4 \\
(0.4999963)\end{array}$ & $\begin{array}{l}54.3 \\
(0.4999876)\end{array}$ \\
\hline$>44$ & $\begin{array}{l}38.3 \\
(0.4841649)\end{array}$ & $\begin{array}{l}37.7 \\
(0.4795407)\end{array}$ & $\begin{array}{l}29.7 \\
(0.4525527)\end{array}$ \\
\hline \multicolumn{4}{|l|}{ Education } \\
\hline Primary & $\begin{array}{l}60.8 \\
(0.4939615)\end{array}$ & $\begin{array}{l}59.1 \\
(0.4950694)\end{array}$ & $\begin{array}{l}41.1 \\
(0.4834259)\end{array}$ \\
\hline Secondary & $\begin{array}{l}26.6 \\
(0.4497743)\end{array}$ & $\begin{array}{l}27 \\
(0.4483107)\end{array}$ & $\begin{array}{l}36.4 \\
(0.4795687)\end{array}$ \\
\hline Tertiary & $\begin{array}{l}12.6 \\
(0.347955)\end{array}$ & $\begin{array}{l}13.9 \\
(0.3583885)\end{array}$ & $\begin{array}{l}22.5 \\
(0.4435706)\end{array}$ \\
\hline \multicolumn{4}{|c|}{ Unemployment duration } \\
\hline$<3$ months & $\begin{array}{l}13.2 \\
(0.3146732)\end{array}$ & $\begin{array}{l}10.7 \\
(0.287438)\end{array}$ & $\begin{array}{l}18.2 \\
(0.3162316)\end{array}$ \\
\hline 3-6 months & $\begin{array}{l}7.9 \\
(0.2724026)\end{array}$ & $\begin{array}{l}5.8 \\
(0.2528136)\end{array}$ & $\begin{array}{l}4.5 \\
(0.2317206)\end{array}$ \\
\hline $6-12$ months & $\begin{array}{l}11.3 \\
(0.3288985)\end{array}$ & $\begin{array}{l}10.6 \\
(0.3307453)\end{array}$ & $\begin{array}{l}11 \\
(0.3462231)\end{array}$ \\
\hline $1-2$ years & $\begin{array}{l}16.7 \\
(0.3806886)\end{array}$ & $\begin{array}{l}18.5 \\
(0.3892842)\end{array}$ & $\begin{array}{l}19.5 \\
(0.415217)\end{array}$ \\
\hline$>2$ years & $\begin{array}{l}50.9 \\
(0.4999269)\end{array}$ & $\begin{array}{l}54.4 \\
(0.499145)\end{array}$ & $\begin{array}{l}46.8 \\
(0.4991007)\end{array}$ \\
\hline
\end{tabular}

about half a percentage point over not receiving any activation intervention in the last 6 months. ${ }^{22}$

The last three columns in Table 7 show the impact of training programmes on job-finding rates. Unfortunately, we have no information on the type of training provided or on whether there is any selection process prior to participating in a training programme. Given this information limitation, all that we can assert is whether participating in any kind of training programme helps individuals find a job. What we find is that training is undoubtedly the factor with greatest impact on

\footnotetext{
${ }^{22}$ The impact of guidance is also addressed for the population subgroups. The results are not shown here as all profiles have similar results, so they are deemed to be of little interest. Training programmes are not assessed for the different population groups for reasons of sample size.
} 
Table 7 Assessment results: impact of activation on the probability of finding a job

\begin{tabular}{|c|c|c|c|c|c|c|}
\hline & \multicolumn{3}{|l|}{ Guidance } & \multicolumn{3}{|l|}{ Training } \\
\hline & IPW & AIPW & PSM & IPW & AIPW & PSM \\
\hline ATT & $\begin{array}{l}0.00543 * * * \\
(0.000601)\end{array}$ & $\begin{array}{l}0.00475 * * * \\
(0.000453)\end{array}$ & $\begin{array}{l}0.00760 * * * \\
(0.000772)\end{array}$ & $\begin{array}{l}0.0297 * * * \\
(0.00233)\end{array}$ & $\begin{array}{l}0.0258 * * * \\
(0.00204)\end{array}$ & $\begin{array}{l}0.0298 * * * \\
(0.00292)\end{array}$ \\
\hline No. Observations & 431,773 & 431,773 & 420,482 & 431,773 & 431,773 & 292,816 \\
\hline Treated individual & 9436 & 9436 & - & 1484 & 1484 & - \\
\hline Treated ind-month & 139,554 & 139,554 & - & 11,888 & 11,888 & - \\
\hline Control individual & 42,309 & 42,309 & - & 50,270 & 50,270 & - \\
\hline Control ind-month & 292,219 & 292,219 & - & 419,885 & 419,885 & - \\
\hline
\end{tabular}

Treated group: unemployed MIS recipients who have received activation services in the last 6 months. Control group: unemployed MIS recipients who have not received any activation services in the last 6 months

$I P W$ inverse probability weighting, $A I P W$ augmented inverse probability weighting, $P S M$ propensity score matching

Robust standard errors in parentheses $* * * p<0.01, * * p<0.05, * p<0.1$

the probability of finding a job for the MIS group. Individuals who use these programmes increase their likelihood of finding a job by around 3 percentage points. Given that the average job-finding rate for MIS recipients is 3\%, the probability of finding a job increases by around $100 \%$ when an unemployed MIS recipient attends a training course. Due to their potential for job finding, it would be most helpful to have more detailed information regarding training programmes so as to assess in the future more precisely in which types of training programme seem to work best.

In line with the literature on active labour market policies, we also find that an adequate design of activation policies accelerates entry into employment. ${ }^{23}$ In short, active policies significantly accelerate the probability of finding a job for MIS recipients. However, only around $40 \%$ of them use such measures, even though participation in them is supposedly compulsory. Specifically, training is the most effective policy: those who undergo it are twice as likely to find a job. This conclusion emphasises the importance of linking passive policies with active policies, because those MIS recipients who use active policies enhance their chances of finding a job compared to similar unemployed people who do not receive any aid.

\section{Summary and conclusions}

In the Basque Country, a minimum income scheme has been in place continuously since 1989. Its main objective is to guarantee all individuals the resources required to cover their basic necessities, and at the same time to provide for their progressive integration into society and employment. Furthermore, in line with

\footnotetext{
${ }^{23}$ Unfortunately, we are not able to measure the impact of the programmes in the long-term due to sample restrictions.
} 
European Council recommendations, the Basque MIS has an interesting feature: recipients are in principle required to participate in active measures to make their entry into employment as fast and successful as possible.

In 2015, there were about 62,000 MIS recipients, $60 \%$ of whom belonged to the group denoted as "registered unemployed" at the public employment service. The rest are workers, non-working persons who for different reasons do not fit into the category of those registered as unemployed. MIS recipients account for $25 \%$ of all the registered unemployed in the Basque Country.

Given that the Basque MIS is a last resort scheme, individuals with low education levels and the (very) long-term unemployed are prevalent among recipients. Specifically, $60 \%$ of MIS recipients have at most primary education and $52 \%$ have been looking for a job for more than 2 years. Unsurprisingly, low education levels and particularly long unemployment durations are the main determinants that delay job finding. Indeed, MIS recipients have an average monthly job-finding rate of $3 \%$, while for unemployed people who do not receive the MIS, the rate stands at $9 \%$.

The first empirical strategy in this paper is to measure whether this difference is solely due to the different composition of the unemployed or whether the MIS delays entry into employment as empirical evidence has proven that passive policies do in general.

The second aim of the paper is to measure the effectiveness of active policies on MIS recipients in terms of their impact on the probability of finding a job. Even though all MIS recipients are supposed to engage in activation measures, the fact is that only around $40 \%$ of them $(16,000$ out of 38,000 unemployed recipients) have done so at any time in the last 6 months. Guidance is the most common service: it is received by $39 \%$ of all unemployed MIS recipients. It is followed at a long distance by training (received by only $2.3 \%$ ). The profiles of the participants differ from one kind of activation measure to another and also with respect to those who do not participate in such services.

Propensity score methods are applied in both assessments. In both analyses, we follow an augmented inverse probability weighting methodology. In the second exercise, we also supplement our assessment with a propensity score matching. Both methodologies help us deal with confounding effects and differences in composition between the treated and control groups in the most suitable way according to the characteristics of the corresponding group.

Our results confirm that on average the MIS does not delay entry into employment, so the difference in the job-finding rates observed is due solely to the different compositions of the treated and control groups. If the analysis is conducted for specific population groups, we find that its impact differs. The undesired delay effect commonly found in passive policies is observed among less educated and younger MIS recipients, but the MIS accelerates entry into employment for medium and high-educated people and for the over $45 \mathrm{~s}$. The heterogeneity effect found across groups highlights the importance of this analysis, so as to design specific activation policies for each population subgroup. To the best of our knowledge, there are no other assessments of similar policy implementations that we could compare our results with. 
The second finding is that all types of public employment activation services have positive impacts on job-finding rates, but the extent of that impact varies from one measure to another: the most effective services are training programmes (which double the probability of finding a new job), followed by guidance services (which increase the probability by around $20 \%$ ). Hence, as a policy device, this study supports the conclusion that training services for MIS recipients should be enforced, as they help recipients to enter employment, which is the ultimate aim of activation measures. Moreover, it is essential to emphasise the importance of linking passive policies with activation measures for recipients.

Acknowledgements We acknowledge financial support from the Spanish Ministry of Education and Science (ECO2015-67105-R).

\section{Compliance with ethical standards}

Conflict of interest The authors declare the absence of conflict of interest.

Human and animal rights This article does not contain any studies with human or animals participants performed by any of the authors.

Informed consent This article does not contain either any information that requires informed consent.

Open Access This article is distributed under the terms of the Creative Commons Attribution 4.0 International License (http://creativecommons.org/licenses/by/4.0/), which permits unrestricted use, distribution, and reproduction in any medium, provided you give appropriate credit to the original author(s) and the source, provide a link to the Creative Commons license, and indicate if changes were made.

\section{References}

Altonji JG, Elder TE, Taber CR (2005) Selection on observed and unobserved variables: assessing the effectiveness of Catholic schools. J Polit Econ 113(1):151-184

Austin PC (2011) An introduction to propensity score methods for reducing the effects of confounding in observational studies. Multivar Behav Res 46(3):399-424

Ayala L, Paniagua M (2016) Behavioral microsimulation of the impact of in-work benefits on female labor supply and income distribution: evidence from Spain. In: Equalitas working paper, vol 39

Ayala L, Rodríguez M (2010) Explaining welfare recidivism: what role do unemployment and initial spells have? J Popul Econ 23(1):373-392

Card D, Levine PB (2000) Extended benefits and the duration of UI spells: evidence from the New Jersey extended benefit program. J Public Econ 78(1-2):107-138

Card D, Kluve J, Weber A (2010) Active labour market policy evaluations: a meta-analysis. Econ J 120(548): 15

Chemin M, Wasmer E (2012) Ex-ante and ex-post evaluation of the 1989 French welfare reform using a natural experiment: the 1908 social laws in Alsace-Moselle. Sciences Po LIEPP Working Paper, 3

Clavet N-J, Duclos J-Y, Lacroix G (2013) Fighting poverty: assessing the effect of guaranteed minimum income proposals in Quebec. Can Public Policy 39(4):491-516

Crépon B, Duflo E, Gurgand M, Rathelot R, Zamora P (2013) Do labor market policies have displacement effects? Evidence from a clustered randomized experiment. Q J Econ 128(2):531-580

Eichhorst W, Konle-Seidl R (2016) Evaluating labour market policy. Institute for the Study of Labor (IZA) No. 9966, Bonn

Frazer H, Marlier E (2009) Minimum income schemes across EU member states: synthesis report. EU Network of National Independent Experts on Social Inclusion. Social Affairs and Equal Opportunities 
Gardeazabal J, Vega Bayo A (2016). The economic cost of armed conflict. University of the Basque Country-Department of Foundations of Economic Analysis II, No. DFAE-II, 2016-01

Gorjón L (2017) The impact of the minimum income scheme on poverty in the Basque Country. In: FEDEA, No. eee2017-24

Gouveia M, Rodrigues CF (2002) The impact of a guaranteed minimum income program in Portugal. Public Finance Manag 2:2

Imbens GW (2004) Nonparametric estimation of average treatment effects under exogeneity: a review. Rev Econ Stat 86:4-29

Jones D, Marinescu IE (2018) The labor market impacts of universal and permanent cash transfers: evidence from the Alaska permanent fund (No. w24312). National Bureau of Economic Research, Cambridge

Lalive R, Zweimüller J (2004) Benefit entitlement and unemployment duration: the role of policy endogeneity. J Public Econ 88(12):2587-2616

Meyer BD (1990) Unemployment insurance and unemployment spells. Econometrica 58(4):757-782

Oster E (2019) Unobservable selection and coefficient stability: theory and evidence. J Bus Econ Stat 37(2):187-204

Rebollo-Sanz YF, García-Pérez JI (2015) Are unemployment benefits harmful to the stability of working careers? the case of Spain. SERIEs 6(1):1-41

Røed K, Zhang T (2003) Does unemployment compensation affect unemployment duration? Econ J 113(48):190-206

Rosenbaum PR, Rubin DB (1983) The central role of the propensity score in observational studies for causal effects. Biometrika 70(1):41-55

Rosenbaum PR, Rubin DB (1985) Constructing a control group using multivariate matched sampling methods that incorporate the propensity score. Am Stat 39(1):33-38

Rubin DB (2001) Using propensity scores to help design observational studies: application to the tobacco litigation. Health Serv Outcomes Res Method 2(3-4):169-188

Salehi-Isfahani D, Mostafavi-Dehzooei MH (2018) Cash transfers and labor supply: evidence from a large-scale program in Iran. J Dev Econ 135:349-367

Schafer JL, Kang J (2008) Average causal effects from nonrandomized studies: a practical guide and simulated example. Psychol Methods 13(4):279

Standing G (ed) (2003) Minimum income schemes in Europe. International Labour Organization, Geneva

Van Ours JC, Vodopivec M (2006) How shortening the potential duration of unemployment benefits affects the duration of unemployment: evidence from a natural experiment. J Labor Econ 24(2):351-378

Publisher's Note Springer Nature remains neutral with regard to jurisdictional claims in published maps and institutional affiliations. 